Volume 8, No.5, September - October 2019

International Journal of Advanced Trends in Computer Science and Engineering

Available Online at http://www.warse.org/IJATCSE/static/pdf/file/ijatcse55852019.pdf

https://doi.org/10.30534/ijatcse/2019/55852019

\title{
CROLIST: A Mobile App for Collaborative Grocery List Management
}

\author{
Noor Syafiqah Ayuni Mohd-Said, Norliza Katuk \\ School of Computing, Universiti Utara Malaysia, Malaysia, k.norliza@uum.edu.my
}

\begin{abstract}
As smartphones serve many purposes, and they are increasingly becoming an integral part of human lives; digital grocery lists created using mobile apps is the most relevant solution to overcome the limitations in paper-based grocery lists. Although the digital grocery lists align with the current human lifestyle and technological trend, they are unable to support collaborative environment in which they do not provide the facility to share a grocery list among household members. Therefore, the existing digital grocery lists require enhancement to support the collaborative function in creating and managing grocery lists. This paper discusses the development of a mobile application (app) for creating and managing a grocery list collaboratively named CROLIST. It is a digital grocery list that can be used by a group of users to generate and manage grocery lists for a household. CROLIST was developed following rapid application development methodology, and an evaluation was conducted to measure the usability of the app in facilitating the creation and management of grocery lists collaboratively. The results of the evaluation suggested that CROLIST is sufficiently usable in terms of usefulness, ease of use, satisfaction, and supporting the collaborative features for the household needs. Nevertheless, the evaluation revealed that the respondents anticipated that the other household members would add unnecessary grocery items to the lists when the collaborative features are available. Further studies are needed for identifying the effective control mechanisms for more usable shared grocery lists.
\end{abstract}

Key words : Grocery, grocery list, collaborative, mobile phones, smartphones

\section{INTRODUCTION}

In the ubiquitous computing environment, technologies such as mobile phones have high potentials to facilitate human daily life activities towards a healthier, easier, and more comfortable life [1],[2]. Smartphones are referred to the modern mobile phones that provide basic communication functions for voice calls and text messaging as well advanced functions such as music player, video player, digital camera, mini personal computer, and navigation tool [3]. Many applications (apps) have been developed to facilitate human daily life activities [4], such as food ingredients recommendation that suggests that people with recipe lists instantly [5]. Further, a grocery list is automatically generated from the recipes [6], which helps people during the grocery shopping process at a grocery store. Many consider grocery shopping a mundane and less exciting task; however, it is an important activity that is a necessary part of human life [7]. Shopping for groceries is a routine that may take place daily, weekly, or monthly. The previous study suggests that there are three phases associated with a grocery shopping list, known as a development stage, a fulfillment (or usage) stage, and an outcome (or post-purchase) stage [8]. The development stage involves the process of generating a grocery list that contains a list of items that need to be purchased by people, where this stage determines how successful a grocery shopping process is accomplished. Grocery lists act as a memory aid during grocery shopping, and a guide to avoid impulse purchases. Further, it also plays a role as a planning tool that manages household planning for meals as well as home expenditure on groceries and foods

A grocery list is also considered as a supporting tool for a grocery shopping process. It can be created by writing the items on a piece of paper or mobile phone's text-processing apps or simply remembering the items in mind [8]. The common practice of generating a grocery list is by writing the items to be bought on a piece of paper. Although the method has been used for ages; nevertheless, a paper grocery list could be easily contaminated by liquids and dirt, difficult in reading handwriting, and may be left at home or even misplaced. The development in smartphones and mobile technology has been a solution to overcome the limitations in paper-based grocery lists where mobile apps can support the process of creating and managing grocery lists more conveniently and flexibly. It is the most relevant solution nowadays as smartphones serve many purposes, and they are increasingly becoming an integral part of human lives. Mobile-assisted grocery shopping has been an important area in consumer behavior studies, which leads to the development of hybrid, intelligent, and multimodal digital shopping lists that are intended to support consumers' shopping processes [7]. The digital grocery lists are created instantly and stored in individual users' smartphones, in which they can be easily retrieved back for updating the items or as a reference during the grocery shopping process. Although the digital grocery lists align with the current human lifestyle and technological trend, they are unable to support a collaborative environment. The current mobile apps for creating digital grocery lists do not provide the facility to share a grocery list among household members. The lists are not able to be updated instantly by other household members who generally consume grocery products in the house and wish to assist in creating a grocery list. It is the main limitation of the existing mobile apps 
for creating and maintaining grocery lists in which it is unable to support household members' needs in managing a shared grocery list together using their own smartphones.

The grocery items in a grocery list may range from cleaning products, pet supplies, meat, dairy products, fruits, vegetables, and personal care products. The products may be consumed by family members (such as the daughters and sons) other than the one who prepared the list (usually the mother). The creator of a grocery list must check the grocery inventory and the current state of grocery usage during the process of generating a list. This process is tedious; hence, it may cause the grocery items to be missed and omitted from the list. However, the family members who directly consume a product could add it to a shared grocery list when it runs out, which makes the process of creating the grocery list more effective, faster, and easier. Managing a shared grocery list between the members of the family is a missing feature in the mobile app for creating a grocery list. Therefore, this paper aims to design and develop a mobile app that can facilitate household members in creating and managing shared grocery lists. This study proposes a collaborative feature in a mobile app for creating a grocery list that is expected to enhance the overall process and experience of creating a grocery list. The next section discusses the background and related studies on grocery lists. Then, in Section 3 , the methodology for designing and developing the mobile app is described. Section 4 explains the detail design and development of a mobile app named CROLIST to support collaborative grocery management. After that, CROLIST has undergone a usability evaluation, as reported in Section 5. In Section 6, the work is concluded, and potential future works are listed.

\section{BACKGROUND AND RELATED STUDIES}

Grocery shopping is considered as daily living skills [9] that is complex, and it involves a person to learn and experience the few steps, including planning, do the shopping, and evaluate the post-shopping activities. In fact, it is a difficult skill to acquire for people with disabilities and should be taught to them as a way to foster independent living [10]. Although people do shopping as a leisure-time activity, many of them do not enjoy the grocery shopping experience [11]. Usually, people do grocery shopping with a grocery list in hand as a memory aid that helps them to buy the grocery items necessary for their household. During the process of creating a grocery list, people accomplish pre-shopping activities such as checking food inventory in the pantry and plan for weekly meals to identify the necessary ingredients to buy. These activities are monotonous and require some amount of effort and time to accomplish that causes the creation of a grocery list difficult considering people's busy life [12]. Even though generating a grocery list requires many other activities to accomplish, the process are frequently undervalued because they are unrealized and unrecognized [7].
Past studies have proven that grocery lists affect in various facets of human life. In terms of health, grocery lists could lead people to have a healthier diet and gain lower body mass index [13]. Brewster et al. [14] suggested that consumers who shopped with a grocery list will read the Nutrition Facts label and have a higher perceived diet quality. Grocery lists also found to be an essential tool for working parents to plan a healthy meal for their preschool children in Canada [15]. They are also used to measure balanced meals among university students' diet [16]. Apart from health benefits, grocery lists are also used as a tool for acquiring writing and mathematics skills among preschool kids in Chile [17]. Other than health benefits, Ahmed and Ting [18] suggested that grocery lists act as a memory support, financial controller, shopping controller, and deviation controller that leads to a goal-directed shopping. In goal-directed shopping, people create grocery lists for necessary items that help them to maintain the budget and avoid unnecessary expenses. Studies on grocery lists are also valuable in understanding consumers' prepurchase intentions [18]. It has been an essential area of studies in marketing and consumer behavior, where researchers predicted the content of consumers' grocery lists to provide information on product demands and trends to retailers [19].

Although grocery lists have many uses, the process of generating a grocery list can be bothersome for people. The simple tasks that are part of a daily routine are considered mundane for many people that makes the purpose undervalued [20]. Therefore, there is a need for generating grocery lists with minimal effort and time [12]. A possible approach is to exploit smartphones that have pervasive and ubiquitous uses. The significant potential of smartphones is providing people to create and manage digital grocery lists [21]. Studies on mobile-assisted shopping lists have been started since the emerging of smartphone technology. Jayawilal and Premeratne [7] categorized mobile-assisted shopping list apps into four categories, namely (1) hybrid shopping lists, (2) intelligent shopping lists, (3) multimodal shopping lists, and (4) Grocery Retrieval System and Mobile services. A literature analysis conducted for this study found many mobile apps designed to support the creation of grocery lists. A mobile app named Cooking Matters Mobile Application (CMApp) [22] provided low-income parents and caregivers with meal planning and preparation that aims to assist them in planning a weekly meal for their children. "MyNutriCart" app was designed to generate healthy grocery lists based on the user's diet, weight, energy requirements, and considering the individual budget and supermarkets' discounts [23]. SmartGrocer; a context-aware mobile app facilitates the creation of grocery lists by considering user's budget, shopping history, and grocery store's promotional items [12]. Another example of a mobile app named 'The Smart Shopping List' developed using the Apriori algorithm enables users to find an ideal supermarket to buy all grocery items in one place [7].

Further advancements in information and communication technology (ICT) facilitate people to manage their daily life activities more efficiently. One example of technology is radio- 
frequency identification (RFID) and the Internet of Things (IoT) that could generate a real-time grocery list automatically [24]. The benefits of digital grocery lists are mixed up. A study by Huang and Yang [25] in 2018 reported an exciting finding where they found digital grocery lists tend to cause consumers to buy thing in a more excessive and spontaneously than handwritten lists. Considering the use of digital grocery lists is still emerging; the effect is still not known when digital grocery lists become mainstream [26]. The other potential of digital groceries could be expended to support collaboration between members of a household in managing the overall grocery shopping process. Past studies suggested that the grocery lists act as a household planning tool where more than one member could participate in grocery shopping.

The collaborative grocery shopping process involves the use of shared lists where the members of a household could contribute to the lists. A household member may be responsible for the household management and the creation of a grocery list; however, other members of the household may also create a list or collaboratively manage the one created by the person responsible for the household management [27],[28]. Other household members can add new grocery items to the lists whenever they remember [29]. A mobile app that is intended for collaborative grocery lists management requires simultaneous updates and mechanisms to update the list on a real-time basis and avoid multiple members from buying the same grocery items [27]. Garvin et al. [22] suggested that making digital grocery lists sharable among household members could rise the usage of such mobile apps. An effort towards supporting collaborative grocery lists management has been found in 'BringMe!', a text-to-app feature in a mobile app grocery management that allows users to share grocery lists with other users [7]. Analysis of the literature also suggested the use of cloud-based tools for collaborative grocery list management among the household members. Household members can create a grocery list using the cloud-based tool, authorize access to the other members, and the other members can add items to the list [3].

Studies on the mobile-assisted grocery list to support collaborative usage is still at its infancy stage. As the use of smartphones becomes prevalent, it is hypothesized that digital grocery lists created and managed collaboratively using smartphones will also gain attention among users soon. Therefore, studies related to the design and development of mobile-assisted grocery list to support collaborative usage among household members is needed. It could help in identifying the general features and communication flows of such an app so that the process of creating and managing grocery lists collaboratively is simplified and pleasant.

\section{METHODOLOGY}

The mobile app for collaborative grocery list management was developed following rapid application development (RAD) methodology, as described by Martin [30]. RAD imcorporates four phases, namely (1) requirement planning, (2) user design, (3) construction, and cutover, as illustrated in Figure 1. The requirement planning involves with the developers gathere the requirements of a mobile app for collaborative grocery list management from the users. The boundary of the project is made based on the collected requirements. The gathered requirements determine the system architecture for the mobile app, and the initial system model is created, which involve in the second phase. The iterative process will happen as often as needed. During the construction phase, the developers develop a prototype that includes the elements and requirements for the mobile app as needed by the users. The functions of the prototype are checked continuously to ensure functionality for the mobile app. This phase also includes app development, coding, and system testing. Finally, in the cutover phase, testing, evaluation, and implementation of the mobile app take place.

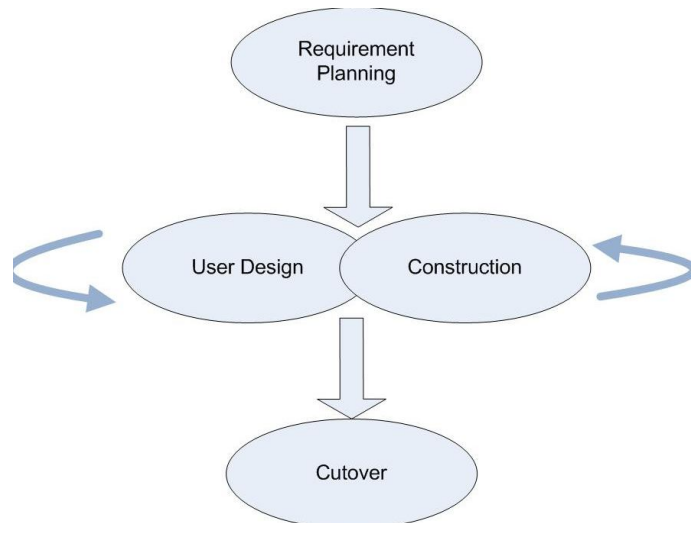

Figure 1:RAD methodology [28]

\subsection{Design and Development of CROLIST}

This section explains the design and development of CROLIST that mapped to the first, second, and third phases of RAD methodology. It combined the requirement planning, user design, and construction of the mobile app.

\subsection{The Basic Requirements for CROLIST}

In a collaborative environment, users should be able to create a grocery list and share the list with the other users within their network, which primarily their family members. For example, a mother of a household could share the list with the father, the daughters, the sons, and perhaps a helper. Figure 2 illustrates an instance of a collaborative network in a family, particularly for creating shared grocery lists. Further, the other members of the family; for example, the daughter could also initiate a list and share the list with the mother or the other siblings. 


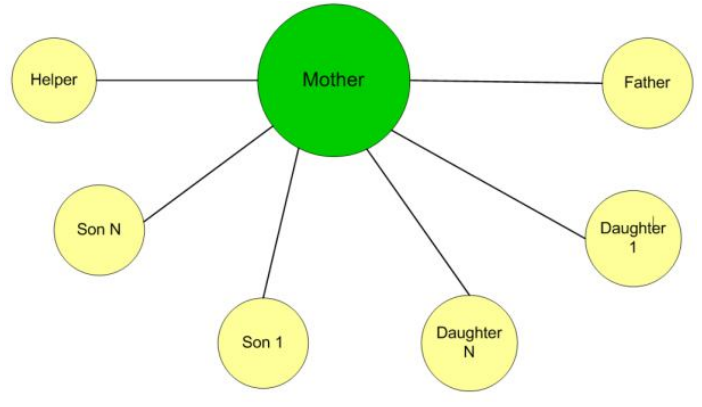

Figure 2: An example of a collaborative network in a family

This fundamental principle of creating shared grocery lists has been included in the requirements of the mobile app. Informal conversations with mothers who used grocery lists during their grocery shopping were carried out to understand how the mobile app should behave, which resulted in acquiring the basic requirements as listed in Table 1 . The level of priority in the Table represented by " $\mathrm{M}$ " as mandatory requirements and "O" as optional requirements.

Table 1: List of basic requirements for CROLIST

\begin{tabular}{|c|c|c|}
\hline Name & Requirements & Priority \\
\hline \multirow{2}{*}{ Login } & $\begin{array}{c}\text { The app shall be able to verify the } \\
\text { username and password for } \\
\text { individual users. }\end{array}$ & $\mathrm{M}$ \\
\hline Edit profile & $\begin{array}{c}\text { The app shall allow users to edit the } \\
\text { username, password, and email. }\end{array}$ & $\mathrm{O}$ \\
\hline \multirow{2}{*}{$\begin{array}{c}\text { Manage } \\
\text { grocery list }\end{array}$} & The app shall be able to create lists. & $\mathrm{M}$ \\
\cline { 2 - 3 } & The app shall be able to delete lists. & $\mathrm{M}$ \\
\cline { 2 - 3 } & $\begin{array}{c}\text { The app shall be able to view lists } \\
\text { with other users. }\end{array}$ & $\mathrm{M}$ \\
\hline $\begin{array}{c}\text { Manage } \\
\text { collaborator }\end{array}$ & $\begin{array}{c}\text { The app shall be able to add other } \\
\text { users as collaborators. }\end{array}$ & $\mathrm{M}$ \\
\hline Log out & $\begin{array}{c}\text { The app shall be able to terminate the } \\
\text { session. }\end{array}$ & $\mathrm{M}$ \\
\hline
\end{tabular}

The basic requirements in Table 1 are transformed into a use case diagram, as shown in Figure 3, to show the interactions between the elements of the mobile app. Two actors are identified as (1) shopper - the key person who performed the grocery shopping at the supermarket, and (2) collaborator - the other users whom the shopper shares the list for adding grocery items. The main use cases for the mobile app are "login", "manage grocery list", "edit profile", "add collaborator", and "log out". Other use cases include "create list", "edit list", "share list", and "delete list" that is extended from "manage grocery list". Further, "sign up" is part if "Login" use case.

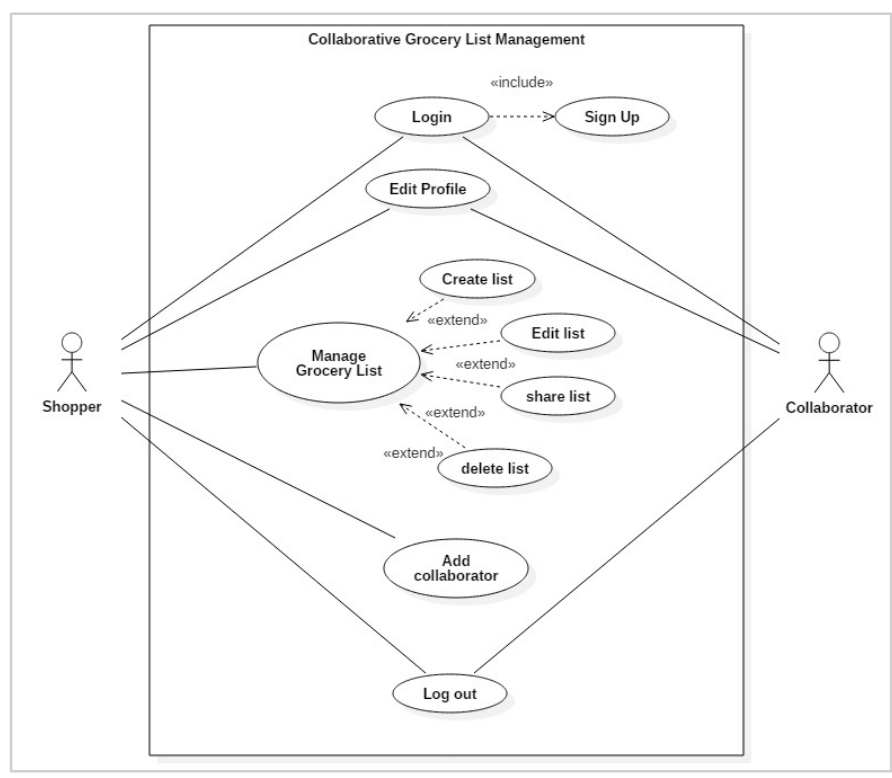

Figure 3: The use case diagram of CROLIST

A class diagram in Figure 4 shows the objects and their attributes of the mobile app, namely shopper, collaborator, item, and list. "Shopper" can manage "List" and "Collaborator". "List" contains many "Items". "Collaborator" can access "List".

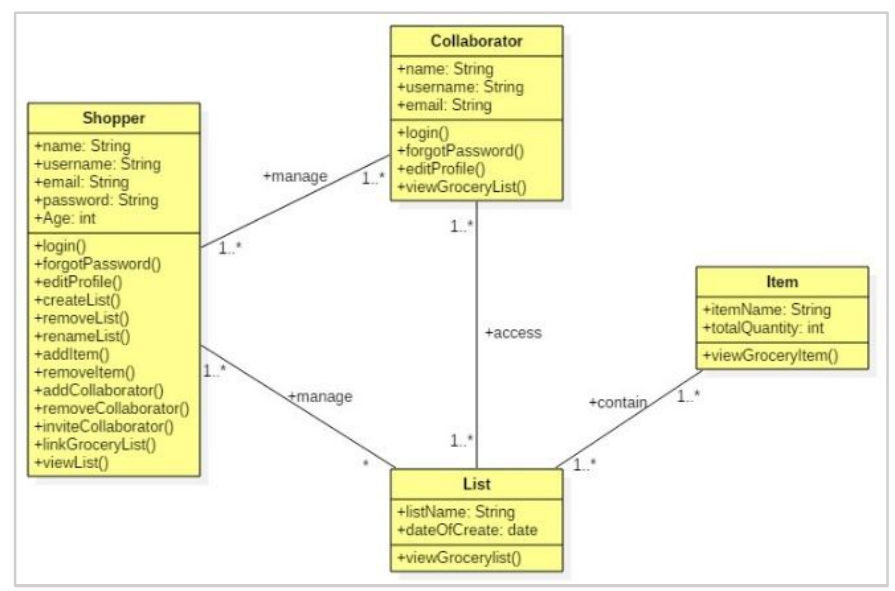

Figure 4: The class diagram for CROLIST

A network diagram illustrated in Figure 5 shows the components of CROLIST and the interactions between them that imitated the client-server architecture. The components include (1) users, (2) smartphone, (3) mobile network, and (4) Firebase. Users installed the mobile app on smartphones that act as a client in the communication model. Then the Firebase hosted the database application and acted as the server. 


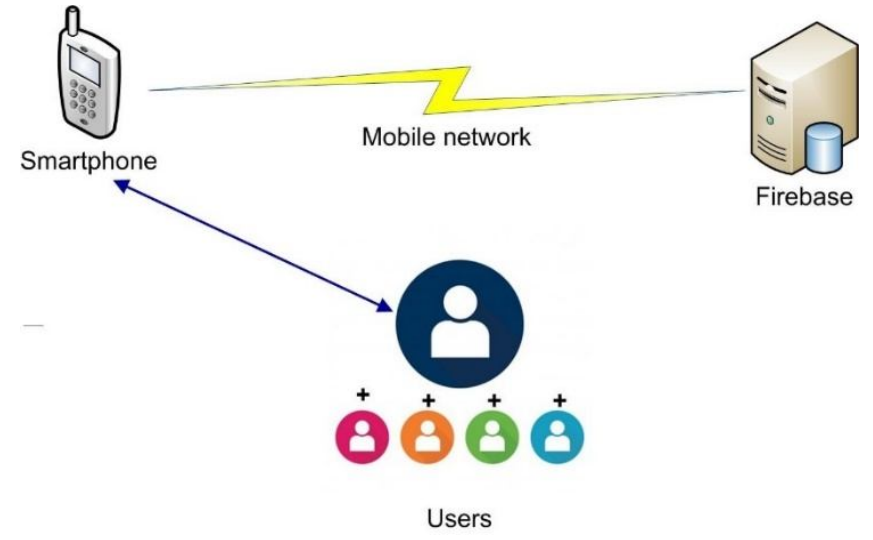

Figure 5: The network architecture for the mobile app

Software architecture (SA) is the essence of software systems in which it has a critical task in the performance of a software system [14]. It contains a representation of how a system is organized and the interactions between components in performing the stated functions [31].

\subsection{Prototype Development}

A prototype was developed to demonstrate the gathered requirements and how the collaborative features work in generating and managing shared grocery lists. It was developed using an online tool named Appybuilder; a drag-and-drop mobile app builder that uses visual programming for developing mobile apps. The prototype was designed in an Android platform with the user data stored in Firebase. The selected interfaces of CROLIST are shown in Figure 6.

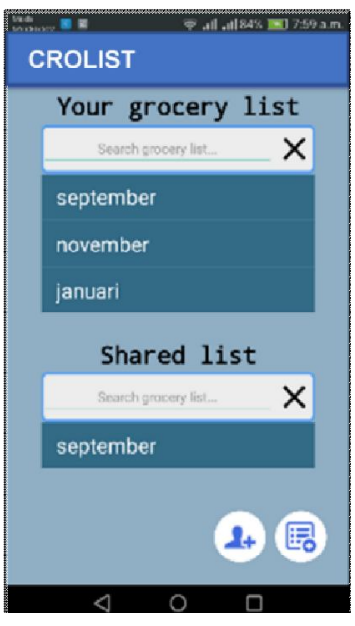

(a) The home interface

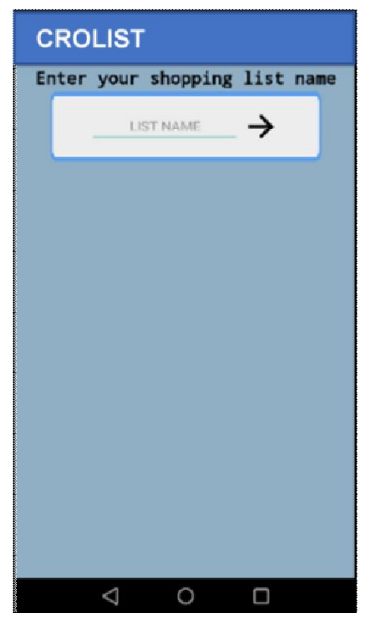

(b) The interface for creating a list
Figure 6: Examples of the CROLIST user interfaces

The screenshot in Figure 6(a) shows the home interface of CROLIST. Once the users successfully login to the system, they will be given the lists they have created and lists shared by other users. A user can create a new list by touching the list-icon located on the bottom right of the screen. Then, they need to type a name for the new list and touch the arrow icon next to the text box, as shown in Figure 6(b). After a new grocery list is created, a user must add grocery items to the list. The default and existing grocery items can be selected by ticking the combo box, as shown in Figure 7(a). Items that are not listed in the combo box can be added to the newly created list by simply typing it at the bottom of the combo box. New categories of grocery items can also be added to the default items. If a user wishes to share a list with the other users, he or she can search the username of the respected users and add them to their potential list of collaborators, as shown in Figure 7(b).

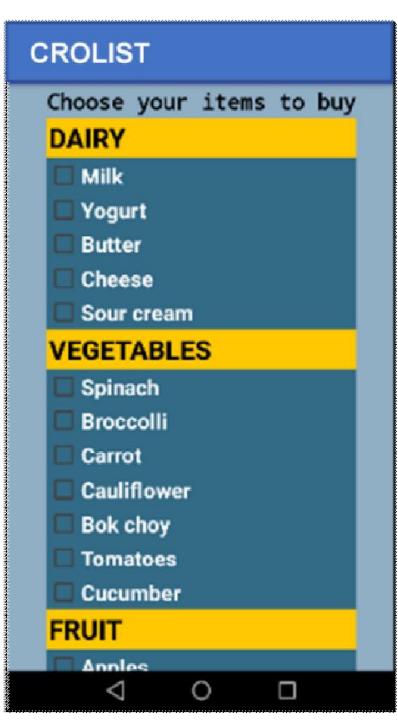

(a) The interface for adding grocery items to the list

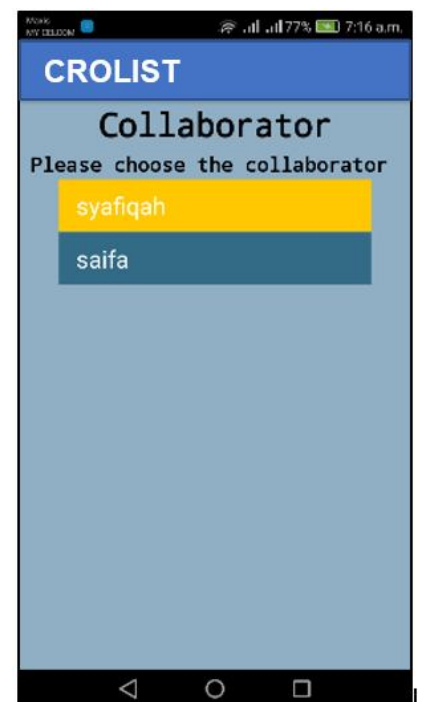

(b) The interface for adding a collaborator
Figure 7: More examples of the CROLIST user interfaces

\section{EVALUATION OF CROLIST}

This section explains the evaluation of CROLIST that mapped to the last phase of the RAD methodology, which covers the cutover phase. One of the critical issues in developing technology or apps is experience [32]; therefore, it is crucial to evaluate the users' experience through the usability evaluation so that the effectiveness of the app can be known.

\subsection{The Evaluation Setting}

A usability evaluation of CROLIST was conducted on 70 respondents during April 2019. They were approached randomly at a supermarket near the university, and they participated in the evaluation voluntarily. During the evaluation, the respondents were provided with CROLIST app installed on a smartphone and a post-task questionnaire adapted from Lund [33]. The post-task questionnaire consists of two sections (1) demographic information and (2) usability of CROLIST. The demographic questions consist of eleven questions, while the usability section has twenty-nine questions. Lund [33] proposed 30 items in four 
categories of usability, namely usefulness, ease of use, ease of learning, and satisfaction. The instrument has been used widely in other usability studies, such as reported in Hussain et al. [34], Lam et al. [35], and Razak et al. [36], which demonstrates a substantial level of construct validity and reliability. However, in this study, only twenty-three items from three categories of Lund's usability items were used, namely usefulness, ease of use, and satisfaction. Six specific questions related to the collaborative features in the mobile app were added to the questionnaire. The questions ask the respondents' opinion on whether the collaborative feature encourages the other family member to assist in managing a shared grocery list and the impact of having a shared list to the overall process of creating and maintaining a grocery list. The respondents rated the usability of the mobile app using a seven-point Likert scale where one represents strongly disagree, and seven represents strongly agree. Instructions and guidance of using CROLIST were given to the respondents during the evaluation to ensure the procedure is carried out smoothly.

\subsection{Analysis and Tools}

The responses given by the respondents were coded in a spreadsheet and analyzed using IBM SPSS Statistics 25. The data are internally consistent as described by the Cronbach's alpha coefficients of 0.953 . Descriptive analyses were carried out on the data as reported in the subsequent sections.

\subsection{The Respondents' Demographic Information}

The respondents of the study consisted of an equal number of married and single status, with $64 \%$ of them were female. $50 \%$ of the respondents aged between 21 and 30 . The pie chart in Figure 8 shows the number of respondents based on their age group. Approximately $70 \%$ of the respondents did grocery shopping. They were also asked about any mobile app for creating and managing the grocery list. Only $23 \%$ of the respondents knew about the mobile app for creating grocery lists.

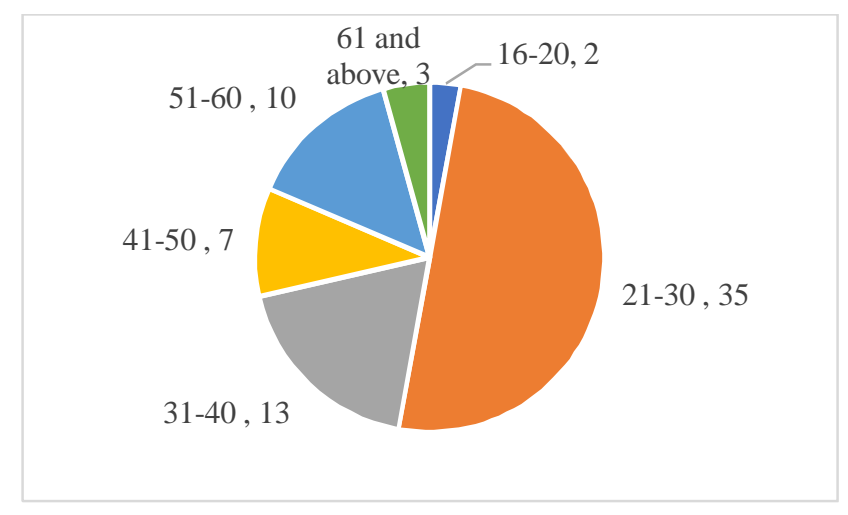

Figure 8: The age group and number of respondents
The evaluation also reported that more than $70 \%$ of the respondents prepared the grocery list before going to the supermarket. $28 \%$ wrote the grocery list on a piece of paper, $26 \%$ just remembering the list in their mind, while $16 \%$ use the app on the smartphone. In terms of preparing the grocery list, $50 \%$ of them had their family members helping in preparing the grocery list.

\subsection{The Usefulness of CROLIST}

The usability of CROLIST is measured through a descriptive analysis of the respective aspects covering the mean, median, and standard deviation (S.D.). In terms of usefulness, eight items were evaluated. In general, the respondents agreed that CROLIST could save their time, which received the highest rating.

Table 2: The mean, median, and S.D. of usefulness aspect for CROLIST $(n=70)$

\begin{tabular}{|c|c|c|c|c|}
\hline Ref. & Questions & Mean & Median & S.D. \\
\hline 1 & $\begin{array}{l}\text { "CROLIST helps me be more } \\
\text { effective in managing } \\
\text { groceries." }\end{array}$ & 4.87 & 5.00 & 1.128 \\
\hline 2 & $\begin{array}{l}\text { "CROLIST helps me to be } \\
\text { more productive." }\end{array}$ & 4.76 & 5.00 & 0.999 \\
\hline 3 & $\begin{array}{l}\text { "CROLIST is useful for } \\
\text { creating grocery lists." }\end{array}$ & 5.04 & 5.00 & 1.135 \\
\hline 4 & $\begin{array}{c}\text { "CROLIST gives me more } \\
\text { control over the activities in } \\
\text { my life." }\end{array}$ & 5.07 & 5.00 & 1.121 \\
\hline 5 & $\begin{array}{l}\text { "CROLIST makes the things } \\
\text { I want to accomplish easier to } \\
\text { get done." }\end{array}$ & 5.10 & 5.00 & 1.287 \\
\hline 6 & $\begin{array}{l}\text { "CROLIST saves my time } \\
\text { when I use it." }\end{array}$ & 5.17 & 5.00 & 1.285 \\
\hline 7 & "CROLIST meets my needs." & 5.00 & 5.00 & 1.319 \\
\hline 8 & $\begin{array}{l}\text { "CROLIST does everything I } \\
\text { would expect it to do." }\end{array}$ & 4.89 & 5.00 & 1.410 \\
\hline
\end{tabular}

\subsection{The CROLIST's ease of use}

An analysis was also made on the eight items for ease of use. The mean of the items ranged between 4.37 and 5.04, while the median was a mixed of 4 and 5, as listed in Table 3. Overall, the respondents agreed that CROLIST was simple to use, which received the highest rating. 
Table 3: The mean, median, and S.D. of ease-of-use aspect for CROLIST $(\mathrm{n}=70)$

\begin{tabular}{|c|c|c|c|c|}
\hline Ref. & Questions & Mean & Median & S.D. \\
\hline 9 & "CROLIST is easy to use." & 4.90 & 5.00 & 1.298 \\
\hline 10 & "CROLIST is simple to use." & 5.04 & 5.00 & 1.160 \\
\hline 11 & "CROLIST is user-friendly." & 4.99 & 5.00 & 1.257 \\
\hline 12 & $\begin{array}{c}\text { "CROLIST requires the } \\
\text { fewest steps possible to } \\
\text { accomplish what I want to do } \\
\text { with it." }\end{array}$ & 4.66 & 5.00 & 1.413 \\
\hline 13 & "CROLIST is flexible." & 4.67 & 5.00 & 1.327 \\
\hline 14 & $\begin{array}{c}\text { "Using CROLIST is } \\
\text { effortless." }\end{array}$ & 4.50 & 4.00 & 1.338 \\
\hline 15 & $\begin{array}{c}\text { "I can use CROLIST without } \\
\text { written instructions." }\end{array}$ & 4.37 & 4.00 & 1.446 \\
\hline 16 & $\begin{array}{c}\text { "Both occasional and regular } \\
\text { users would like CROLIST." }\end{array}$ & 4.63 & 4.50 & 1.287 \\
\hline
\end{tabular}

\subsection{The Respondents' Satisfaction with CROLIST}

An analysis was also made on the seven items of the respondents' satisfaction in using CROLIST. The mean of the items ranged between 4.29 and 4.59 , while the median was four, as listed in Table 4. Generally, the respondents satisfied with CROLIST, which received the highest rating.

Table 4: The mean, median, and S.D. of satisfaction aspect for CROLIST $(n=70)$

\begin{tabular}{|c|c|c|c|c|}
\hline Ref. & Questions & Mean & Mean & S.D. \\
\hline 17 & $\begin{array}{c}\text { "I am satisfied with } \\
\text { CROLIST." }\end{array}$ & 4.59 & 4.00 & 1.234 \\
\hline 18 & $\begin{array}{c}\text { "I would recommend } \\
\text { CROLIST to a friend." }\end{array}$ & 4.63 & 4.00 & 1.287 \\
\hline 19 & "It is fun to use CROLIST." & 4.57 & 4.00 & 1.303 \\
\hline 20 & $\begin{array}{c}\text { "CROLIST works the way I } \\
\text { want it to work." }\end{array}$ & 4.51 & 4.00 & 1.225 \\
\hline 21 & $\begin{array}{c}\text { "CROLIST is wonderful." } \\
22\end{array}$ & 4.50 & 4.00 & 1.164 \\
\hline 23 & $\begin{array}{c}\text { "I feel that I need to have } \\
\text { CROLIST." }\end{array}$ & 4.29 & 4.00 & 1.331 \\
\hline & $\begin{array}{c}\text { "It is pleasant to use } \\
\text { CROLIST." }\end{array}$ & 4.46 & 4.00 & 1.326 \\
\hline
\end{tabular}

\subsection{The collaborative features of CROLIST}

Finally, an analysis was made on the six items of the respondents' collaborative features offered by CROLIST. The mean of the items ranged between 4.74 and 5.07, while the median was five, as listed in Table 5. The respondents claimed that a collaborative list might contain unnecessary items added by their family members, which received that highest rating.
Table 5: The mean, median, and S.D. of collaborative aspect for CROLIST $(\mathrm{n}=70)$

\begin{tabular}{|c|c|c|c|c|}
\hline Ref. & Questions & Mean & Median & S.D. \\
\hline 24 & $\begin{array}{c}\text { "CROLIST encourages my } \\
\text { family members to participate } \\
\text { in planning for grocery } \\
\text { shopping." }\end{array}$ & 4.87 & 5.00 & 1.006 \\
\hline 25 & $\begin{array}{c}\text { "CROLIST allows me and } \\
\text { my family working together } \\
\text { in identifying grocery items } \\
\text { necessary to us." }\end{array}$ & 4.74 & 5.00 & 1.212 \\
\hline 26 & $\begin{array}{c}\text { "My family members can } \\
\text { easily add items that I forgot } \\
\text { into the grocery list provided } \\
\text { by CROLIST." }\end{array}$ & 4.84 & 5.00 & 1.150 \\
\hline 27 & $\begin{array}{c}\text { "My family members tend to } \\
\text { add unnecessary items into } \\
\text { the grocery list of } \\
\text { CROLIST." }\end{array}$ & 5.07 & 5.00 & 1.220 \\
\hline 28 & $\begin{array}{c}\text { "My grocery list can be } \\
\text { created in a shorter time } \\
\text { because my family members } \\
\text { help in generating the list } \\
\text { using CROLIST." }\end{array}$ & 4.90 & 5.00 & 1.287 \\
\hline 29 & $\begin{array}{c}\text { "CROLIST makes my job } \\
\text { easier for preparing the } \\
\text { grocery list." }\end{array}$ & 4.93 & 5.00 & 1.322 \\
\hline
\end{tabular}

The descriptive statistics presented in Tables 2-5 suggested that CROLIST is sufficiently usable with most of the usability aspects received a median value of five out of the seven scales. CROLIST is useful as it received the highest median rating as compared to the ease of use and satisfaction. Further, it encouraged the family members to participate in planning for a grocery list and working together to generate the lists in a shorter time, which makes the task of creating the list easier. Family members can also add missing items on the list. However, the major drawback of the shared grocery lists is that the family members could add unnecessary items to the lists.

\section{CONCLUSION AND FUTURE WORKS}

This paper described the development and evaluation of CROLIST; a mobile app for creating and managing a grocery list with a group of users who shared the lists. The evaluation of the mobile app suggested exciting findings that could encourage more studies in improving the design and communication flows of mobile apps for supporting the creation and management of grocery lists collaboratively among household members. The mobile app can be improved by incorporating social network identity and authentication to add collaborators using the identified networks easily. Further, a more efficient technique for adding the grocery items to the list can be done by incorporating optical character recognition or incorporating IoT for sensing the grocery items that are running out of stock in the pantry or fridge. Further, more studies are needed to identify the 
efficient way of controlling the items in the list when multiple users are working together to manage the lists.

\section{ACKNOWLEDGMENT}

The research is funded by the Ministry of Higher Education, Malaysia under the Trans-Disciplinary Research Grant Scheme (Ref: TRGS/2/2014/ UUM/01/3/4, UUM S/O Code:13170).

\section{REFERENCES}

1. M. Achouri, A. Alti, M. Derdour, S. Laborie, and P. Roose. Smart fog computing for efficient situations management in smart health environments, Journal of Information and Communication Technology, vol. 17, pp. 537-567, 2018.

https://doi.org/10.1145/3167020.3167022

2. P. Deshwal, P. Khattar, A. A. Srivastava, and N. Kakkar. Mobile learning readiness and time of daily use, International Journal of Advanced Trends in Computer Science and Engineering, vol. 8, 2019.

3. N. Katuk, N. H. Zakaria, and K. R. Ku-Mahamud. Mobile Phone Sensing using the Built-in Camera, International Journal of Interactive Mobile Technologies, vol. 13, pp. 102-114, 2019.

https://doi.org/10.3991/ijim.v13i02.10166

4. A. Baharum, N. H. Nazlan, N. A. M. Noor, R. Hanapi, I. Ismail, and N. A. M. Noh. Information Visualization for Food Mobile Application: Hangri 2.0, International Journal of Advanced Trends in Computer Science and Engineering, vol. 8, pp. 306-314, 2019.

5. K. Yanai, T. Maruyama, and Y. Kawano. A Cooking Recipe Recommendation System with Visual Recognition of Food Ingredients, International Journal of Interactive Mobile Technologies, vol. 8, pp. 28-34, 2014. https://doi.org/10.3991/ijim.v8i2.3623

6. W. Koo. Usage of Smartphone Applications: A Descriptive Study of Top 100 US Retailers, International Journal of Interactive Mobile Technologies (iJIM), vol. 10, pp. 54-58, 2016.

https://doi.org/10.3991/ijim.v10i3.5827

7. H. Jayawilal and S. Premeratne. The smart shopping list: An effective mobile solution for grocery list-creation process, in The Proceedings of 2017 IEEE 13th Malaysia International Conference on Communications (MICC), 2017, pp. 124-129.

8. R. Bassett, B. Beagan, and G. E. Chapman. Grocery lists: connecting family, household and grocery store, British Food Journal, vol. 110, pp. 206-217, 2008. https://doi.org/10.1108/00070700810849916

9. A. Stabel, "Daily Living Skills," in Encyclopedia of Autism Spectrum Disorders, F. R. Volkmar, Ed., ed New York, NY: Springer New York, 2013, pp. 839-840.

10. V. Gil, K. D. Bennett, and P. M. Barbetta. Teaching Young Adults with Intellectual Disability Grocery Shopping Skills in a Community Setting Using Least-to-Most Prompting, Behavior Analysis in Practice, pp. 1-5, 2019.

11. R. Reid and S. Brown. I hate shopping! An introspective perspective, International Journal of Retail \& Distribution Management, vol. 24, pp. 4-16, 1996.
12. R. Jain. SmartGrocer: a context-aware personalized grocery system, Master of Science, Department of Computer Science, University of Victoria, 2018.

13. J. A. Seabrook, P. D. N. Dworatzek, and J. I. Matthews. Predictors of Food Skills in University Students, Canadian Journal of Dietetic Practice and Research, pp. 14, 2019.

14. P. J. Brewster, C. M. Durward, J. F. Hurdle, G. J. Stoddard, and P. M. Guenther. The Grocery Purchase Quality Index-2016 Performs Similarly to the Healthy Eating Index-2015 in a National Survey of Household Food Purchases, Journal of the Academy of Nutrition and Dietetics, vol. 119, pp. 45-56, 2019/01/01/ 2019.

15. E. M. Piras and A. Zanutto. Prescriptions, x-rays and grocery lists. Designing a Personal Health Record to support (the invisible work of) health information management in the household, Computer Supported Cooperative Work (CSCW), vol. 19, pp. 585-613, 2010. https://doi.org/10.1007/s10606-010-9128-5

16. J. Morrissey. Financial Socialization and Its Effects on Food Insecurity Among College Students, Master of Arts, The Graduate College, University of Nebraska, 2019.

17. D. Leyva. How Do Low-Income Chilean Parents Support Their Preschoolers' Writing and Math Skills in a Grocery Game?, Early Education and Development, vol. 30, pp. 114-130, 2019/01/02 2019.

18. S. Ahmed and D. H. Ting. The shopping list in goaldirected shopping: scale development and validation, The Service Industries Journal, vol. 39, pp. 319-342, 2019/04/26 2019

19. S. Peker, A. Kocyigit, and P. E. Eren. An empirical comparison of customer behavior modeling approaches for shopping list prediction, in 2018 41st International Convention on Information and Communication Technology, Electronics and Microelectronics (MIPRO), 2018, pp. 1220-1225.

20. J. Polaski. We Know You Want It: Perspectives on Predictive Shopping, Honors Thesis in Management Bridgewater State University, 2015.

21. B. E. Kahn, J. J. Inman, and P. C. Verhoef. Introduction to Special Issue: Consumer Response to the Evolving Retailing Landscape, Journal of the Association for Consumer Research, vol. 3, pp. 255-259, 2018. https://doi.org/10.1086/699389

22. T. M. Garvin, A. Chiappone, L. Boyd, K. Stern, J. Panichelli, L. A. E. Hall, et al. Cooking Matters Mobile Application: a meal planning and preparation tool for low-income parents, Public health nutrition, pp. 1-8, 2019.

23. C. Palacios, M. Torres, D. López, M. A. Trak-Fellermeier, C. Coccia, and C. M. Pérez. Effectiveness of the Nutritional App "MyNutriCart" on Food Choices Related to Purchase and Dietary Behavior, A Pilot Randomized Controlled Trial. Nutrients, vol. 10, 2018.

24. A. Azizi, "Modern manufacturing," in Applications of Artificial Intelligence Techniques in Industry 4.0, ed: Springer, 2019, pp. 7-17.

25. Y. Huang and Z. Yang. Write or Type? How a Paper versus a Digital Shopping List Influences the Way 
Consumers Plan and Shop, Journal of the Association for Consumer Research, vol. 3, pp. 396-409, 2018. https://doi.org/10.1086/698877

26. L. M. Sloot. Commentary: The Impact of Digitization on Grocery Retailing: Why Shopping Lists Might Be a Valuable Tool for Brick-and-Mortar Grocery Retailers, Journal of the Association for Consumer Research, vol. 3, pp. 410-411, 2018.

27. N. Katuk, T. Jayasangar, and Y. Yusof. Design and Development of Smart List: A Mobile App for Creating and Managing Grocery Lists, Baghdad Science Journal, vol. 16, pp. 462-476, 2019.

28. F. Heinrichs, D. Schreiber, and J. Schöning. The hybrid shopping list: Bridging the gap between physical and digital shopping lists, in Proceedings of the 13th international conference on Human computer interaction with mobile devices and services, 2011, pp. 251-254.

29. M. Janaki. Real World Tour of Cloud Computing for Family, International Journal of Education and Management Engineering, vol. 7, p. 24, 2017. https://doi.org/10.5815/ijeme.2017.06.03

30. J. Martin. Rapid application development: Macmillan Publishing Co., Inc., 1991.

31. M. M. Qasim, M. Ahmad, and M. Omar. Analyzing Persuasive Mobile Healthcare Architecture Using
Systematic Process Design, Journal of Telecommunication, Electronic and Computer Engineering, vol. 9, pp. 77-84, 2017.

32. W. Ahmad, W. Nooraishya, and N. M. Ali. The impact of persuasive technology on user emotional experience and user experience over time, Journal of Information and Communication Technology, vol. 17, 2018.

33. A. M. Lund. USE Questionnaire: Usefulness, Satisfaction, and Ease of use, Usability interface, vol. 8, pp. 3-6, 2001.

34. A. Hussain, M. N. F. A. Razak, E. O. Mkpojiogu, and M. M. F. Hamdi. UX evaluation of video streaming application with teenage users, Journal of Telecommunication, Electronic and Computer Engineering (JTEC), vol. 9, pp. 129-131, 2017.

35. M. C. Lam, S. S. M. Nizam, H. Arshad, S. A'isyah Ahmad Shukri, N. C. Hashim, H. M. Putra, et al. A usability evaluation of an interactive application for halal products using optical character recognition and augmented reality technologies, in AIP Conference Proceedings, 2017, p. 020084.

36. M. N. F. A. Razak, A. Hussain, and M. M. F. Hamdi. Usability study of youtube websites for Malaysian teenagers, in AIP Conference Proceedings, 2017, p. 020121 . 